\title{
Transfer, transformation, transition: what the school librarian can do in transliteracy, the French context
}

\author{
Anne Lehmans \\ Bordeaux University, School of Education, \\ Bordeaux Montaigne University \\ ESPE d'Aquitaine, 33705 Mérignac \\ France \\ anne.lehmans@u-bordeaux.fr \\ Valentine Mazurier \\ Bordeaux University, School of Education, \\ Bordeaux Montaigne University \\ ESPE d'Aquitaine, 33705 Mérignac \\ France \\ valentine.mazurier@u-bordeaux.fr
}

\begin{abstract}
With the emergence of digital information, the school library as a physical location still exists but its spaces and boundaries are reshuffled. This major change encourages us to study the new distribution of spaces in school libraries, the relationships between different types of spaces (physical and digital, individual and social, private and public) and the way pupils move from one to the other. Information transliteracy is the topic of a research project led in France. Our research points out the transformation of learning strategies in collaborative situations, transfers between informal personal digital abilities and formal academic skills and between experts and novices, transition from learning to creating, cognitive redistribution between spaces. We explore and try to explain some of these processes which seem to us encouraging for the future of school libraries and signs of a renewal of the task of librarians, implying new modes of action which we will describe: mediation, creation, education.
\end{abstract}

Keywords: Transliteracy, school library, teacher librarian, mediation, knowledge format.

\section{Introduction}

Information literacy can be defined as series of abilities that can be connected to various ways of seeking, selecting, finding, scrutinizing, organizing and compiling information for meaningful use in late modern society, where people are expected to use information for constructing new knowledge (Limberg, Sundin, Talja 2013). It is based on a humanistic and 
universalistic conception of the right to be educated (Lehmans, 2007) and the project to make education a path to individual empowerment towards information. Recently, information literacy has been completed and enlarged by the concept of transliteracy that Sue Thomas (2007), defines as the ability to read, write and interact across a range of platforms, tools and media from signing and orality through handwriting, print, TV, radio and films, to digital social networks. According to Vincent Liquète (2012), the concept of transliteracy focuses the attention on the "trans" prefix: transversality of skills and abilities common to all media contexts and techniques, transformation of situations and information by personal practices and procedures, transition from personal to collective knowledge, transgression of academic standards. It is at the crossroad of three main fields: information, media and computer literacies, as well as a metaliteracy. Digital literacy, computer literacy, information literacy, and media literacy are no longer isolated.

The concept of transliteracy has been evolving and already impacted the organization of spaces, resources, and teaching by school librarians. It is related to the transmedia and culture convergence theory (Jenkins, 2006) describing the layering, diversification and interconnectivity of media, and it points out the importance of interaction skills applied by users on all types of media and communication, oral, textual, iconic, digital, mainly in digital environments (Delamotte, Liquète, Frau-Meigs, 2014, 146). The way pupils at school access to and use information, which is available anytime and anywhere, has changed learning strategies and the relationship between information and knowledge. Library professionals have to accommodate to this new informational ecosystem inside and outside the walls of the library.

In France, in every secondary school, a teacher librarian is in charge not only of the school library management and organization, but also of education on information. Even if the teacher librarian does not usually follow a precise curriculum, he plays an important role in information and media literacy. He is dedicated to the training of information literate pupils, which is a prerequisite for the sustainable development according to the Moscow Declaration (2012), and for their integration in the knowledge society demanding the skills to ask questions about the construction and dissemination of particular media artefacts. (boyd, 2014 : 181). We try to question the way the concept of transliteracy, which has precise theoretical roots, has been transforming the understanding of school libraries' and teacherlibrarians' action in and on education.

Information transliteracy is the topic of a research project led in France, Translit. School libraries have long been places dedicated to collect, storage, access and preservation of printed collections. With the emergence of digital information, the school library as a physical location still exists but its spaces and boundaries are reshuffled. This major change encourages us to study the new distribution of spaces in school libraries, the relationships between different types of spaces (physical and digital, individual and social, private and public) and the way pupils move from one to the other. Our research points out the transformation of learning strategies in collaborative situations, transfers between informal personal digital abilities and formal academic skills and between experts and novices, transition from learning to creating and from creating to learning, cognitive redistribution between spaces. These phenomena are facilitated by, and sometimes created by the action of the teacher librarian. 
We intend to explore and try to explain some of these processes which seem to us encouraging for the future of school libraries and signs of a renewal of the task of librarians, implying specific modes of action which we will describe: mediation, creation, education.

\section{Mediation by space organization and transfer process}

School librarians are mediators in different ways: socially -between school disciplines, teachers, families, institutions, and pupils regarding skills and expertise-, informationally between documents and users-, cognitively, developing instrumental skills with tools and devices, facilitating situated and shared knowledge creation in spaces. In the context of transliteracy, space is a key component to consider. It is not an empty frame, it does influence pupils' uses. To encourage interaction, exploration and shared knowledge creation, James Paul Gee (2004:73) proposes the concept of "affinity space " as " a place or set of places where people affiliate with others based primarily on shared activities, interests, and goals, not shared race, class culture, ethnicity, or gender ". School librarians ' actions of mediation may focus on space to propose a third space, an autonomous, incentive but not intrusive space.

\section{Methodology and research design: space in the pupils' information ecosystem} In the research project we are working on, we have tried to characterize typical transliterate activities which are cognitively distributed and situated. Our scientific protocol is based on an "ecological" approach of capturing pupils' information retrieval and production practices, and teachers' training practices. We focus on environments and interactions in the phenomenographic tradition (Limberg et al., 2013), considering the social, ideological, and physical contexts and environments in which information and technical artefacts are used' (Tuominen et al., 2005, 340). For this project, we observe the information activities of young people in school project situations, especially in school libraries. Our research, based on ethnographic qualitative methodologies, enables us to observe in details thin and elaborate cognitive phenomena and social relations taking place in the pupils' information working process, especially when digital tools allow them to expand the walls of the classroom and the library.

The teacher librarian in France is in charge of the school library in middle and high schools, called Center for Documentation and Information, which is supposed to support pupils and teachers in their need of information. It provides not only books related to school work, but also leisure literature - or at least literature which may give them the desire to read-, and digital resources. The teacher librarian is in charge of information literacy, education on media and information, culture and communication, bibliotheconomy. The emergence of digital technologies in everyday life has questioned the role of school in the use of tools which can at the same time be useful to get needed information for academic or professional work, and be damaging to the attention and safety of children and personal freedom. Most $\mathrm{CDI}$ are equipped with computers, but digital uses and practices differ from school to school, depending on equipment and access to the internet, the policies of the headmasters, and the capacity of the teacher librarian to manage the use of these computers. Thereby, the CDIs can be considered as unifying spaces for the pupils, and even mediating spaces: with the same spatial organization, the same codes and the same tools, they provide a familiar informational structuring environment where pupils can expect the help and training of an 
information professional. Many discipline programs mention the $\mathrm{CDI}$ as a place where pupils are supposed to go, get information and work with, especially when they work on projects. The real space is often completed with a virtual space, either on a virtual office where pupils can find documents, or on a web site where the teacher librarian organizes documentation through special pages. Some teacher librarians also use social networks, creating a Facebook or a Twitter account for the CDI, in order to disseminate information using familiar tools or to educate pupils to the use of these networks.

Nobody doubts that pupils develop informal information uses and skills in their private, personal leisure activities. But researchers (Fluckiger, Bruillard, 2008) point out a limited transfer between these skills and formal ones inside the walls of the classroom and, by extension, the school library, contrary to the assertions of Mark Prensky's "digital natives" theory. The use of academic digital workspaces which seems to fit pupils' habits and practices remain quite limited at home. Besides, teachers are sometimes still reluctant to use digital tools and favor broadcasting media (Guichon 2012). It is as if personal, digital and informal space on one hand and academic space, on the other hand, were impervious. This is why mediation action seems to be necessary. School librarians develop different mediation devices. Fabre and Gardies (2010) point out the distinction between intentional device and attribution device. The teacher librarian builds the first one using professional standards and skills in order to organize and disseminate information. When pupils appropriate the second one, it conveys meaning. The mediation action of school librarians is to create devices enabling pupils to play an active role in their information literacy learning process. These devices are various but they all serve the same purpose: to help with the ability to embrace the multimedia layout that encompasses skills for reading, writing, counting and computing with all the available tools (from paper to image, from book to blog); and the capacity to navigate through multiple domains that includes the ability to search, to evaluate, to test, to validate, and to modify information according to its relevant contexts of use (as code, news and document) (ANR, 2012).

Web based platforms are specific devices among others. They are likely to enable pupils to find an in-between space: a digital space proposing academic and more informal resources. Pupils can access the platform at home and in the walls of the school. This type of tool can play a positive role of frontier. Border is often considered as a physical limit but it is also a relation and a link, a boundary-object (Star, 2010) between print and digital collections, print and digital uses, private and social spaces. To what extent do pupils benefit from this type of device? Does it enlarge spaces and practices as school librarians may assume?

To answer these questions, we made an inquiry in the context of a junior high school located in Bordeaux with thirteen-years old pupils with heterogeneous academic levels. We collected qualitative material resorting to semi-structured interviews and observation of pupils' uses of the web-based platform inside the school library. The platform is "Scoop-It", a widely spread platform in the educational field and especially in school libraries. It enables professionals to curate and publish content. The interface is seducing, it contains both images and short texts to present web pages. It is quite easy to update. The web pages suggested on the platform come from the school librarian's choices. They are selected according to the criteria of quality and reliability, free information, match to school syllabus and pupils' main interests and information needs considering pedagogical projects and news.

Mediation as a complex process of boundaries creation for information and competencies transfers

As teenagers spend a lot of time on the internet, we assumed that the platform was transparent to them and quite easy to understand and master. What we observed is rather 
different. Pupils' answers to our survey show that they are not comfortable with it: $35 \%$ find it "difficult" to use. They have difficulty to understand how it works - its intellectual organization but also its technical functioning-. Most pupils are not able to define it at once and $40 \%$ of them simply answer «I don't know » when asked to describe it. No pupil can say that it has been created by the teacher librarian. It confirms that, at that age, pupils have a poor knowledge of the internet as a whole and of the teacher librarians' tasks. They do not understand the organization of the home page while it is very important for the librarian to make it readable and efficient. The technical facets are not as easy as we may think for pupils to describe. One pupil says: "You need to push to access information". Another one even says he doesn't know how to access the web pages. Observing pupils in the library confirms that they have difficulty to understand and to use this tool. They hardly browse the website. They examine neither pages nor topics. They target a single page. They skim the page through and their use is extremely limited. It confirms that skills, even the basic ones, are not inborn. But it also sheds light on the device as an additional layer to access information. Instead of making it easier, the platform adds difficulty and may widen the gap between pupils. No pupil consulted the Scoop-It platform at home or on their own in the library even if $95 \%$ of them found it useful at school. The reason is the same for all of them, even if they formulate it in different ways: "I don't think of it" or "I forget". Only $10 \%$ express their lack of interest. They clearly distinguish private use and academic use. One pupil state : "At home, I never visit websites for school". Even if they all declare using the internet every day at home, only $30 \%$ of the sample use the internet at home for school.

We know that listening to music is one of the most widespread leisure activities among teenagers. However, the link to Deezer was not used at all. This site was directly linked to a project led with another group in music lessons. Thus, not one of the pupils activated the link. It highlights the question of information need. If there is no direct information need for school, the resource is not consulted, which is quite easy to understand. Thirteen-years old pupils' relationship to knowledge is still in construction. They are building their own autonomy and tools can't replace it. It also shows that even if music is familiar to them, it remains a private activity that teenagers do not want to introduce at school except in their earphones.

The project points out the fact that boundaries not only concern uses and skills but also time and space. The development of digital information which is supposed to abolish time and space borders could reinforce them in reality. Space may even be an additional barrier and constraint to develop transliterate uses and skills inside the walls of the school, and teacher librarians can't ignore it. Fabre (2013) shows that the distribution of spaces in French school libraries is constraining because it splits medium and, consequently, use. It compartmentalizes information uses, and even organizes it in a hierarchy, instead of favoring mobility. At another level, French researchers Roselli and Perrenoud (2010) led a research project on Toulouse University library and point out how space planning, but also sorting, and professionals, create genuine but invisible frontiers inside the library. The way teacher librarians foresee passage from one to another requires some reflection. Both school librarians and pupils have difficulty to move original boundaries. "Bring Your Own Device" (BYOD) may be a chance to think over space issue. It reshuffles boundaries and changes the way pupils relate to space, mixing informal skills and formal environment, mobile technologies and physical location, private and social spaces.

It could be interesting to conduct the same study with older pupils. Secondary school time is a transitional period leading to more autonomy. Guichon (2012) points out that high school pupils use social networks to solve homework difficulty all together, for example by publishing Facebook status. Teachers can't be aware of this specific collaborative use 
because they simply do not know, refuse or ignore it. Reflection on a specific space for homework may be a first step to bridge the gap between informal and formal skills, private and social spaces as it is situated at the crossroads of home and school. Transliteracy may be an opportunity for school librarians to propose new space affordances to ensure a real information culture.

\section{Creation by knowledge formats and transformation process}

In a part of our research dedicated to sixteen years old high school pupils working on group projects, we were able to evaluate the pupils' capability to organize their information environment, to coordinate the work among the members of the groups and to use various information strategies in order to achieve a creative project. There is a direct correlation between these capabilities and the success of the projects. The supply of adequate knowledge formats in project scenario is a way to combine individual and collective strategies, tools and spaces in the process of knowledge creation.

\section{Conditions for creative learning}

Education in France is based mainly on the mastering of disciplinary, patrimonial and formal knowledge. Project based education is still quite rare and late in the school curriculum. Pupils are used to meet the demands of teachers with very formal strategies, without resorting to creative springs. These are mobilized at home, or clandestinely at school, during or between courses, in non-formal practices. Elisabeth Schneider (2012) shows that students have writing practices which design complex journeys during classes, away from the eyes of teachers, mobilizing complex skills and transmedia activities.

Yet digital tools appear as a means of fostering creativity so little encouraged at school, because it is, in the imagination of pupils, associated with private practices, games, communication. When a teacher encourages personal skills for school use, pupils can take to move the boundaries they usually oppose the demands of the teachers.

Nonetheless, our research has shown that they do not easily use their personal skills and do not "naturally" make bridges between their private uses and academic demands. They have to be encouraged and work in strong groups where they can rely on each other. When asked why they do not rely upon their personal skills, some answer that they do not want to mix school life and leisure, and that it would kill the pleasure to use tools such as a blog or Facebook. They have to be encouraged to "have fun" with their school work in order to allow themselves the right to use their ordinary creation practices, image creation and mixing, video and music making, creative writing. We have observed some teachers who did so and encouraged pupils in this way, while others were too demanding on academic forms to allow any creative process.

It appears that it is important to valuate unformal, private skills and tastes, to give consciousness and confidence to pupils into their own capabilities and also to their understanding and critics. Similarly, while pupils often find information through images (via Google image or YouTube), they do not appear to them as legitimate sources of information: a movie, a video or an image is used only with the encouragement of teachers but not spontaneously. The image is a research format, but rarely a legitimate knowledge building size or disclosure. Moreover, if most pupils have integrated the importance of authorship in high school, and the need to cite sources, they do so only for written sources. For still images or movies, questioning the author seems to disappear behind an informational status of the image blur difficult to question. The images belong to the personal world of leisure and intimacy, the 
text to the school and knowledge world. There is a gap between actual cognitive processes and representation of legitimate knowledge. This shift is reinforced by the sense of generational gap. The bridge is so difficult to build between the informational universe of the web, shifting and blurring, and school communication formats and legitimacy. Several examples illustrate these blocking in legitimacy. For example, bibliographies, which are often webographies, are mostly built as copied and pasted url lists, except when a specific instruction is given and explained by the teacher-librarian. The use of copy-paste is considered illegitimate, except when teachers see it as a first phase in the work of collecting information, followed by a writing and reformulation phase. Formats are sources of reflection on legitimacy.

\section{Forms, formats and transformation}

Knowledge formats allow the establishment of communicative conditions and provide frameworks for the emergence of transliterate skills. A format is a tangible and intangible knowledge organization model, linking "logic of knowledge and dynamic of uses" (Morandi, 2013, 139). It designs forms to knowledge and information questioning (mind maps), work organization (logbooks), information management (indexing) or communication (books, web documentaries, blogs...). The logbook, for example, is mandatory in some projects but often reduced to a formal and unnecessary requirement. Some teachers have transformed this requirement by explaining it as an effective information storage tool and work organization. When it exists, the book may be strictly organized by some pupils with a color code system, and often used to store and manage the references of key documents and ideas that are useful to the editor. It sometimes becomes, at the initiative of the teacher librarian, a true cognitive and didactic training tool. The logbook is a tool for storage, sharing and documentation of found information. It allows to organize information at the end of the project, a heuristic for retrieved media information to operate and maintain the correct references. Logbooks of pupils we observed in high schools also reflect the diversity of research tools and communication skills. A pupil, for example, explains in his diary that he synthetized information in English combined with video clips of presidential speeches for his subject on the U.S. elections. He adds that he wanted to propose an oral presentation based on an animated slide show, mixing music clips and photo montage. His logbook shows quite a complex hybridization of practices monitoring academic prescription (standardized references as prescribed by the teacher librarian) and communicative creativity and support on its common research and communication practices. Formats can also be offered in a prescriptive guide blog and was effective in our observations from one year to another, to guide pupils in their choice of tools and document description formats. Finally, a specific communication format allows pupils to think about alternative ways of rendering a research and reduces the contradictions they perceive between familiar multimedia fixtures and academic formats used at school (written presentation). This is the case for radio, video, data visualization or blog productions in media classes. These formats may open pupils to the design of information through content production, they do not only solicit academic knowledge, but critical thinking, not just problem solving, but also issues discovering.

Despite what is commonly said on pupils' information practices, they own an elaborate "art of doing" (de Certeau, 1980) and a strong consciousness of their uses and the management of their personal information system. They tend to invent ways of doing things which are not orthodox according to what they are taught, but nonetheless efficient and explicable using thoughtful devices. They need to be mentored in the process of transfers of uses and expertise among them. We use the word grammatization of information to characterize the process of creative learning, construction of knowledge and competencies on information 
which lead to information culture or transliteracy. This grammatization appears when pupils are induced to think about their own practices and criticize them according to their social, academic and individual needs, constructing formal from informal knowledge on information, media and computers. It relies on two conditions: the existence of intuitive but nonetheless efficient information practices, commonly acquired in social situations, and the presence of a teacher librarian who induces awareness and control of the practices through conscience knowledge formats. When one of these conditions is lacking, the process cannot be completed. It was the case in some situations that we observed: when pupils have no or poor social experience of using media information and when the teacher librarian has few occasions to interact with them, a strong difference among pupils is observed, which creates inequality: in this case, transliteracy will mainly depend on social conditions and not on education. In the third case, while the pupils' social conditions are not favorable to transfers between personal and school information practices or between different media, the role of the teacher librarian is important to compensate the lack or poverty of informal knowledge.

\section{Transition and education process}

Educational support to media, digital and information literacy is the sine qua non condition of equality in transliteracy and promotion of democracy at school. Our observations show that pupils are very unequal regarding access to and use of information. They also need to develop their critical sense. A more or less formal curriculum is necessary to ensure a real «information culture » based on transliteracy among pupils.

\section{Education in transliteracy as a social construction}

The fundamental role of teacher librarians is to guarantee the emancipation of the individual, conscience and knowledge production. This emancipatory function appears all the more essential that the cultural and cognitive "legacy" of students is unequal, depending on the geographical location and the social composition of the school. In the vocational school we observed, students are those of much greater difficulties than others to construct knowledge from information and from personal and informal practices. In this situation, digital tools make the social and cognitive gap wider, and education in essential.

The digital gap between pupils is so important that a systematic effort on education has appeared as a necessity. We observed different schools in which the educational strategies were quite different. The problem is that information and media literacy are not included into a formal program but cross different programs in which the teachers do not always pay equal attention to information competencies. In training schools, it may have dramatic consequences, because most pupils do not have access to knowledge on information in their families or social groups. Under the vocational school, the process of mutual enrichment between personal, social and academic practices is complicated, either because non-formal information practices are poorly developed, mainly for entertainment, or because the school format is not mastered by pupils: the transition from spontaneous information and communication practices to school knowledge requires significant support from the teacherlibrarian. Some mechanisms may still be unlocked when letting, for example, pupils seek information from images, or Wikipedia, and encouraging them to link the information found with their personal observations on the professional field, or with a collective reflection involved in the group with the teachers. 


\section{Education as an activity-based transition process}

Finally, the role of teacher librarians facing the ever-changing information environments relies in their ability to draw knowledge path from the non-formal and multimedia practices. Our study shows how the spontaneous and ordinary information and communication practices are a lever for educational action. Moreover, teacher librarians met during our investigations tend to encourage and value these practices, which is rarely the case for teachers from traditional disciplines who tend to reproduce a closed discourse centered on prohibitions and restrictions, nor for librarians who are more interested in the information searching processes than in its use for learning (Limberg, Sundin, Talja, 2013). On one hand, the discipline teachers only consider the content of knowledge produced and not of its mode of production, which is a source of tension between the teachers themselves. On the other hand the librarians, especially at university, do not pay attention to the cognitive processes and rely on procedures and tools. Information literacy, as Christine Bruce (1997) has clearly demonstrated, is not uniform but engaged into various experiences and constructions of information uses.

From the beginning of their history, French teacher librarians have tried to assume pedagogical strategies. Their actions focus on skills to empower pupils to become enlightened and critical information literate citizens in an unstable and information overloaded environment. Knowledge mediation is even more on the agenda as people often confuse information and knowledge, access and skill. Researchers and field actors develop a set of information and documentation didactic notions. They promote the idea of a curriculum to ensure a real and solid "information culture". They use various learning situations. Distance learning is also an interesting path which starts to be used by some teacher librarians who build personalized courses (Lehmans, Cordier, 2012) based on collaboration between pupils. This field of research is still under construction but it already shapes school librarians actions, tools and mediations. The lack of a precise academic program forces them to concentrate their action on activities, processes and projects prior to a locked knowledge content. The transliteracy perspective engages them into a renewed reflection on the architecture of school learning and information literacy (Cordier, Liquète, 2013) taking into consideration social and technical interactions and transfers, and the need of creative mediation processes. The theory of activity (Engeström, 2014), based on the socioconstructivist legacy, reminds the centrality of the cognition processes in the use of information as socially situated and distributed into the activity understood as a process of production and meaning construction.

\section{Conclusion}

Transliteracy, observed in educational and informational contexts, features a transformation of learning strategies and porosity between academic skills and "intuitive" competencies, formal and informal. This transformation of the constitutive rules of schoolwork and redistribution of cognitive and social roles, skills and knowledge in building transliterate strategies, highlight the need to support knowledge formats, informational activities, and new forms of pedagogical mediation allowing the meeting of spontaneous informal practices with formal requests and legitimate and inclusive cultural constructs.

\section{References}

ANR TRanslit (2012). Présentation. Available at: http://www.univ-paris3.fr/presentation-anrtranslit-317833.kjsp [accessed 10/3/2015]. 
Boyd, d. (2014). It's complicated: the social lives of networked teens. New Heaven: Yale University Press.

Bruce, C. (1997). The Seven Faces of Information Literacy. Adelaide: Auslib Press.

Certeau, M. (de). (1980) L'Invention du quotidien, 1. : Arts de faire. Paris: Gallimard.

Cordier, A., Liquete, V. (2013) La translittératie, un facteur de réagencement de l'organisation scolaire ?. 19ème Colloque Bilatéral Franco-Roumain en Sciences de l'Information et de la Communication, Mar 2013, Romania. Available at: http://archivesic.ccsd.cnrs.fr/sic 01066402 [accessed 10/3/2015].

Delamotte, É., Liquète, V., Frau-Meigs, D. (2014) La translittératie, ou la convergence des cultures de l'information : supports, contextes et modalités, Spirale, 53, 145-156.

Engeström, Y. (2014) Learning by Expanding: An Activity-Theoretical Approach to Developmental Research. Cambridge: Cambridge U.P.

Fabre, I. (2013). L'espace documentaire comme lieu de médiations. Esquisse. Available at : http://oatao.univ-toulouse.fr/9136/1/Fabre 9136.pdf [accessed 10/3/2015].

Fabre, I., Gardies, C. (2010). La médiation documentaire. In Médiations, Les essentiels d'Hermès, Institut des sciences de la communication du CNRS (ISC), 121-139.

Fluckiger, C., Bruillard, E. (2008). TIC : analyse de certains obstacles à la mobilisation des compétences issues des pratiques personnelles dans les activités scolaires. Available at: http://archivesic.ccsd.cnrs.fr/sic 00343128 [accessed 10/3/2015].

Gee, J. P. (2004). Situated Language and Learning: A Critique of Traditional Schooling. London: Routledge.

Guichon, N.(2012). Les usages des TIC par les lycéens - déconnexion entre usages personnels et usages scolaires, STICEF, Vol.19, Available at : http://sticef.org [accessed 10/3/2015].

IFLA, UNESCO (2012). The Moscow Declaration on Media and Information Literacy. Available at: http://www.ifla.org/publications/moscow-declaration-on-media-andinformation-literacy [accessed 10/3/2015].

Jenkins, H. (2006). Convergence Culture: Where Old and New Media Collide, New York: NYU Press.

Lehmans, A. (2007). Information Literacy : un Lien entre Information, Education et Démocratie. Esquisse, 50-51, 25-40.

Lehmans, A., Cordier, A. (2012) Distance learning as a central issue for the learning and professionalization process of professeurs documentalistes: The French synthesis 
of transliteracy. School Libraries Worldwide, International Association of School Librarianship, 18(2), 41-50.

Limberg, L, Sundin, O., Talja, S. (2013). Three Theoretical perspectives on Information Literacy, Human It, 11(01).

Liquète, V. (2012). Can one Speak of an "Information Transliteracy"? International Conference Media and Information Literacy (MIL) for Knowledge Societies, 24-28 June, Moscow, Russian Federation, Available at : http://www.unesco.org/new/fileadmin/MULTIMEDIA/HQ/Cl/Cl/pdf/ln Focus/Liquete text.pdf [accessed 10/3/2015].

Roselli, M., Perrenoud, M. (2010). Du lecteur à l'usager : ethnographie d'une bibliothèque universitaire. Toulouse: Presses universitaires du Mirail.

Star, S.L. (2010). This is not a boundary object: Reflections on the origins of a concept. Science, Technology and Human Values, 35(5), 601-617

Schneider, E. (2012) Pratiques d'écriture adolescentes et translittératie. GRCDI (Groupe de Recherche sur la Culture et la Didactique de l'Information) Séminaire du 7 septembre 2012 : La translittératie en débat : regards croisés des cultures de l'information (infodoc, médias, informatique) et des disciplines. Available at: http://culturedel.info/grcdi/wp-content/uploads/2012/09/Seminaire-GRCDI2012 texte-E.Schneider.pdf [accessed 10/3/2015].

Thomas, S and al. (2007). Transliteracy. Available at:

https://suethomasnet.wordpress.com/transliteracy / [accessed 10/3/2015].

Tuominen, K., Savolainen, R. \& Talja, S. (2005). Information literacy as a socio-technical practice. Library Quarterly, 75(3), 329-345.

\section{Biographical notes}

Anne Lehmans has worked as associate professor at Bordeaux University (School of Education) since 2003. She holds a PhD in Political Science. She holds and coordinates courses on information literacy and information and communication science. She takes part of the selection board of teacher librarians for the French Minister of Education. She is a project manager for digital uses at the School of Education in Bordeaux university. She is involved into several research projects among which Translit (Convergence between media, digital, information literacies). Her most recent contributions were in Media and Education Futures Conference in Tampere (Finland) with Vincent Liquète in Conditions for a Sustainable Information Transculture and in the European Conference on Information Literacy 2014 in Dubrovnik (Croatia) with Anne Cordier in Transliteracy and knowledge formats. She is one of the authors of the book Culture of information recently published by Vincent Liquète (CNRS, Essentiels Hermès, 2014).

Valentine Mazurier has been a teacher librarian in Bordeaux since 1999. She is a PHD student in Information and Communication Science (under the direction of Pr Vincent Liquète). Her research subject focuses on the documentary space in the French context of 
school libraries through the study of representations and practices of teacher-librarians and pupils in terms of space. She takes part in the teacher librarian training at the School of Education in Bordeaux. She has been a selection board member of teacher librarians (CAPES) for the French Minister of Education (2007-2010). 